\title{
High Norepinephrine Status Induced Growth of Colorectal Cancer With Type 2 Diabetes Mellitus Benefited From ADP-Ribosyltransferase 1
}

\author{
Wenwen Chen \\ Chongqing Medical University \\ Yanping Yang \\ Chongqing Medical University \\ Jiale Duan \\ Chongqing Medical University \\ Ming Li \\ Chongqing Medical University \\ Yi Tang \\ Chongqing Medical University \\ Shuxian Zhang \\ Chongqing Medical University \\ Hanjuan Gong \\ Chongqing Medical University \\ Qingshu Li \\ Chongqing Medical University \\ Yalan Wang ( $\sim$ 100475@cqmu.edu.cn) \\ Chongqing Medical University https://orcid.org/0000-0002-5430-2552
}

\section{Research}

Keywords: ADP-Ribosyltransferase 1, diabetes, norepinephrine, colorectal cancer, AKT

Posted Date: September 30th, 2020

DOI: https://doi.org/10.21203/rs.3.rs-82525/v1

License: (c) (i) This work is licensed under a Creative Commons Attribution 4.0 International License. Read Full License 


\section{Abstract}

Background

It is known that type 2 diabetes mellitus patients have higher susceptibility to colorectal cancer and poorer prognosis, but the mechanism is quite unknown. Here, we investigated effect of ADP-Ribosyltransferase 1 on growth of colorectal cancer combined diabetes in high norepinephrine status and the potential mechanism.

Methods

We evaluated size and weight of transplanted tumors with different ADP-Ribosyltransferase 1 level of CT26 cells or different norepinephrine level on diabetic mice model and observed their survival time as well. Consistently, CCK8 and flow cytometry were applied for detecting growth of CT26 cells in vitro. Western blot was performed for analyzing differentially expressed proteins of proliferatic profiles to determine ADPRibosyltransferase 1-modulated pathway.

Results

According to our data, high level of norepinephrine and ADP-Ribosyltransferase 1 both facilitated proliferation of CT26 cells in vitro and in vivo, besides, inhibition of norepinephrinee-depended-proliferation was observed in ADP-Ribosyltransferase 1 silencing CT26 cells in vitro compared with CT26 cells with ADPRibosyltransferase 1 expression. However, we discovered after reducing norepinephrine level of serum by surgery, size and weight of the transplanted tumors were significantly reduced compared with non-operated group and sham-operated group. Further, expression of ADP-Ribosyltransferase 1, mTOR, STAT3, p-AKT protein in tumor tissues of diabetic mice was increased rather than non-diabetes mice, while after depleting norepinephrine level by renal denervation operation, expression of proliferation-relative proteins mTOR, STAT3, p-AKT protein was decreased, but no change was discovered in ADP-Ribosyltransferase 1 expression. While under the same concentration of norepinephrine environment, ADP-Ribosyltransferase 1 boosts expression of p-AKT, mTOR, STAT3, CyclinD1 and c-myc in CT26 cells in vitro.

Conclusions

This study proposed a hypothesis that high-norepinephrine-induced proliferation of colorectal cancer required expression of ADP-Ribosyltransferase 1, and raise ADP-Ribosyltransferase 1 might be a candidate target for treatment of diabetes-associated colorectal cancer.

\section{Introduction}

At present, many studies have shown that type 2 diabetes mellitus (T2DM) is closely related to the occurrence and development of colorectal cancer (CRC). Compared with non-diabetic patients, T2DM patients have an increased risk of colorectal cancer and death, with a poor prognosis, but its specific mechanism is not very clear $[1,2,3]$. 
Insulin resistance (IR) is the pathophysiological basis of T2DM. IR can activate the sympathetic nervous system (SNS), resulting in increased level of circulating norepinephrine (NE) $[4,5,6]$. The long-term activation of SNS leads to the onset of metabolic syndrome and increases the risk of T2DM, which can further aggravate IR, causing a vicious cycle $[7,8,9,10]$. A large number of studies indicate that NE can activate adrenergic receptors, in CAMP-PKA, AKT-mTOR, ERK-Mnk1 and other signaling pathways, thereby affecting the downstream signaling molecules STAT3, c-myc, MMP-2 expression and activity and thus affect the biological behavior of tumor cells. The role of NE may be inhibited when the level of NE changes or use the alpha and beta-receptor blocker to affect the activity of beta-adrenergic receptors on the surface of tumor cells $[11,12,13,14,15,16,17]$. Therefore, T2DM with high level of NE induced activation of signaling pathways such as AKT/mTOR/STAT3, which might be a potential mechanism of patient suffering T2DM with higher risk of CRC.

ADP-ribosyltransferase-1 (ART1), an important single ADP ribose transferase, catalyzes the posttranslational modification of proteins by transferring a single ADP ribose group to the arginine residue of the protein, is believed to have a closely related to a variety of cellular biological behaviors $[18,19]$. In the early stage, we reported that ART1 expression changes altered the phosphorylation level of AKT, as well as the activity and expression of mTOR, GSK-3, c-myc, then affected the proliferation, invasion, metastasis, differentiation, angiogenesis and apoptosis of colon cancer CT26 cells $[20,21,22]$. AKT signaling pathway is one of the important pathways of cell survival, but also the important insulin signaling pathway. Activation of AKT can promote mTOR, STAT3 and other downstream substrate phosphorylation and exert extensive biological effects, suggesting that ART1 is associated with glucose metabolic diseases. However, the effects and mechanisms of ART1 on the growth of T2DM with high NE status in colorectal cancer have not been reported.

Here we illuminate whether ART1 affect AKT/mTOR/STAT3 signaling pathway and intervene its downstream genes expression such as CyclinD1 and c-myc through the regulation of AKT, subsequently influencing tumor growth and proliferation in T2DM and CRC double attacked patients accompany with high level of NE, and what is the crosstalk between ART1 and NE.

\section{Materials And Methods}

\section{Cell lines and animals}

CT26 cell line was obtained from Professor Yu-Quan Wei (Sichuan University, Chengdu, Sichuan, China), having successfully constructed ART1-short hairpin RNA (GFP-shRNA), ART1-over-expression (GFP-ART1) and vector-control (GFP-Vector) CT26 cells $[\mathbf{2 3 , 2 4 ]}$. All cell groups were cultured in RPMI-1640 medium (Hyclone, Logan, UT, USA) supplemented with 10\% fetal bovine serum (FBS), $100 \mathrm{U} / \mathrm{ml}$ penicillin and 100 $\mu \mathrm{g} / \mathrm{ml}$ streptomycin (Hyclone) at $37^{\circ} \mathrm{C}$ in a $5 \% \mathrm{CO}_{2}$ incubator.

BALB/c mice (6-8 weeks old,18-22 g) were obtained from the animal experimental center of Chongqing Medical University (Chongqing, China) and placed in the specifi pathogen-free feeding room $\left(20-26^{\circ} \mathrm{C}, 12\right.$ $\mathrm{h}: 12 \mathrm{~h}$ light-dark cycle) of the animal experimental center at Chongqing Medical University. Mouse were then 
randomly divided into two groups and fed either a normal-chow diet (NCD) or a high-fat diet (HFD). The NCD (catalog no. 5001, Research Diets Inc., New Brunswick, NJ, USA) provided 59\% calories from carbohydrates, $20 \%$ from protein, and $19 \%$ from fat, $14.61 \mathrm{KJ} / \mathrm{g}$. The HFD (catalog no. 9398, Research Diets Inc) contained $30 \%$ of calories from carbohydrates, $18 \%$ from protein, and $50 \%$ from fat, $19.75 \mathrm{KJ} / \mathrm{g}$.

All experimental procedures were approved by the Animal Experimentation Ethics Committee (Chongqing Medical University) and in accordance with the National Health and Medical Research Council of China Guidelines on Animal Experimentation.

\section{CT26 cell survival assays and Flow cytometry analysis}

CCK8(CCK8 kit, Key Gen Biotechnology, Nanjing P R China) method was used to evaluate the influence of ART1 on the CT26 cell proliferation in different concentrations $(0,0.2,0.4,0.6,0.8,1.0 \mu \mathrm{M})$ of NE for 24 or $1.0 \mu \mathrm{M}$ of NE for $12 \mathrm{~h}, 24 \mathrm{~h}, 36 \mathrm{~h}$ or $48 \mathrm{~h}$. The absorbances (optical densities) were recorded with a universal microplate reader (Bio-Tek) at $450 \mathrm{~nm}$. The assays were repeated at least three times.

The flow cytometry (Becton Dickison) assessment was used to evaluate the cell cycle distribution of each

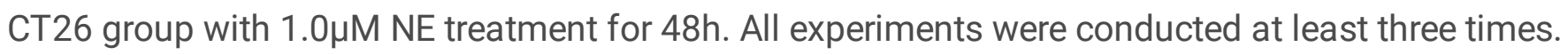

\section{Establishment of diabetic mouse model}

A diabetic Balb/c mouse model was established by feeding with high fat diet for six weeks and $1 \%$ streptozotocin (STZ, Sigma Chemical Co, St Louis, USA) 50mg/kg intraperitoneal injection, while Balb/c mice with normal diet were injected intraperitoneally with saline as control. Diabetes was defined as a random glucose $\geq 11.1 \mathrm{mmol} / \mathrm{L}$ in tail vein blood (test strips, Advantage, Bayer, Contour TS), one week after STZ injection $[25,26,27]$.

\section{Subcutaneously transplanted tumor model}

Each experimental group consisted of 12 mice. CRCD group(n=48): T2DM Balb/c mice, feeding with HFD, were randomly divided into 4 groups, 1区GFP-ART1 group, subcutaneously transplanted GFP-ART1 CT26 cell; 2هGFP-shART1 group, subcutaneously transplanted GFP-shART1 CT26 cell; 3囚Un-transfection group, subcutaneously transplanted Un-transfection CT26 cell; 4囚GFP-Vector group, subcutaneously transplanted GFP-Vector CT26 cell. CRCO group $(n=48)$ : Balb/c mice without T2DM, feeding with NCD, were randomly divided into 4 groups, $1 \llbracket$ GFP-ART1 group, subcutaneously transplanted GFP-ART1 CT26 cell; 2هGFP-shART1 group, subcutaneously transplanted GFP-shART1 CT26 cell; 3凶Un-transfection group, subcutaneously transplanted Un-transfection CT26 cell; 4『GFP-Vector group, subcutaneously transplanted GFP-Vector CT26 cell.

CT26 cell suspension $\left(2 \times 10^{6} / \mathrm{ml} \times 200 \mu \mathrm{l}\right)$ was subcutaneously injected into the lateral skin of the right armpit of each mouse [30]. After 14 days, six mice were randomly selected from each group for sacrifice, and the weight and volume of the subcutaneous tumor was recorded. The survival time of the rest of the mice in each group was recorded. Tumor volume was calculated according to the formula: Volume=the maximum diameter $x$ the most trails $2 \times 1 / 2[31]$ 
Another 12 diabetic Balb/c mice inoculated with GFP-ART1 CT26 cells, were further divided into three groups: (1) left RD (LRD, $n=4$ ) (2) left sham operation ( $L S O, n=4)(3)$ without operation (GFP-ART1 group, $\mathrm{n}=4)$. RDs or sham surgeries were performed as described previously $[\mathbf{2 8 , 2 9 ]}$. In brief, mice were anaesthetized with an intraperitoneal ketamine injection $(87 \mathrm{mg} / \mathrm{kg})$. Following paravertebral line incision, kidneys were exposed and the renal arteries and veins were isolated from connective tissue. After stripping the visible nerves, the vessels were painted for 2 min with a solution of $10 \%$ phenol in absolute ethanol. The muscular layers of the abdominal wall were sutured with absorptive material and the skin was closed by non-absorptive filament. Animals recovered from anesthesia 10-20 min after the end of surgery. In sham operation, animals the renal nerves were isolated but preserved. As described earlier [29], correct denervation was assessed by measuring the renal tissue content of catecholamines using a ELISA KIT (Cloud-Clone, USA). Completeness of denervation was assumed if the norepinephrine tissue content was $<10 \%$ of the mean value in the sham-operated groups [28].

Second days after the operation, the mice recovered, were inoculated with GFP-ART1CT26 cells on the right axillary fossa. After 2 weeks, the mice were killed. Kidneys and xenografted tumor were removed, weighing and measuring the tumor volume, they were frozen together in the liquid nitrogen to reserve. Besides, blood was obtained to measure.

\section{Western blot analyses}

The total proteins of cells and Balb/c mice transplantation tumors of the colorectal cancers were lysed with lysis buffer (Beyotime, Shanghai, China).

Protein was electrophoresed on SDS-PAGE gel and transferred to PVDF membranes. The membranes were blocked with $5 \%$ non-fat dried milk and incubated respectively with primary antibodies overnight at $4{ }^{\circ} \mathrm{C}$ including ART1 (Abgent, San Diego, CA, USA;1: 500 dilution), Akt kinase (Akt), phospho-Akt (p-AKT), STAT3, mTOR, CyclinD1, c-myc (Cell Signaling Technology, MA, USA; 1: 1000 dilution), then, incubated with horseradish peroxidase-conjugated secondary antibody at a dilution of 1:1000 (ZSGB-BIO, Beijing, China). Finally, the membranes were assessed using enhanced chemiluminescence reagents (ECL) (Beyotime) and analyzed with Quantity One software (Bio-Rad Laboratories, CA, USA). $\beta$-actin was used as a loading control for the western blotting experiments.

\section{Other analytical Procedures}

Insulin and NE levels of serum were measured by commercial enzyme-linked immunosorbent assay kit (Cloud-Clone, USA) according to the manual.

\section{Statistical analysis}

Statistical data was analyzed by SPSS 19.0 software (SPSS, Chicago, IL, USA). Enumeration data were checked by chi square test. Binary logistic regression analyzed the correction of T2DM and ART1 expression in CRC patients. All values are presented as means $\pm S E$. Unpaired Student t-test was used for two-group 
comparisons. A one-way ANOVA was using to compare among groups, followed by a least significant difference post hoc test to compare between groups. Differences were considered statistically significant at $P<0.05$.

\section{Results}

\section{High concentration of NE boosted proliferation of CT26 cells requiring of ART1 expression}

Each group of CT26 cells with various expression level of ART1 (GFP-ART1, Un-transfection, GFP-Vector and GFP-ShART1 group CT26 cells) was induced for 24 hours at the end concentration of $0.2,0.4,0.6,0.8$ and 1 $\mu \mathrm{M}$ NE respectively. The results showed that with the increase of the concentration of NE, proliferation was raised gradually in groups of CT26 cells expressing ATR1 (GFP-ART1, Un-transfection and GFP-Vector groups), but not in ATR1 silenced CT26 cells (Figure 1A). We further studied the time-depend of NE on proliferation of GFP-ART1, Un-transfection, GFP-Vector and GFP-ShART1 group. Each group was treated with $12,24,36,48 \mathrm{~h}$ at the end concentration of $1 \mu \mathrm{M} \mathrm{NE}$, respectively. The data showed that cell proliferation activity of GFP-ART1, Un-transfection and GFP-Vector groups were all increased depend on prolongation of treatment time (from $12 \mathrm{~h}$ to $36 \mathrm{~h}$ ), while treated for $48 \mathrm{~h}$, proliferation regress of these group was detected. But no conspicuous difference was measured in GFP-ShART1 group with prolongation of treatment time

(Figure 1B). On the other hand, flow cytometry result showed that comparing with Un-transfection group and GFP-Vector group, ratio of G1 phase was decreased, while S phase and PI were increased in GFP-ART1 group, on the contrary, increased ratio of G1 phase and decreased of S phase and PI were detected in GFPshART1 group. After NE induction, the result showed decreased percentage of G1 phase as well as increased percentage of $\mathrm{S}$ phase and the cell proliferation index of $\mathrm{PI}$ in groups of CT26 cells expressing ATR1 (GFP-ART1, Un-transfection and GFP-Vector groups). Still no obvious difference in cell cycle distribution and PI for ATR1 silenced CT26 cells (Figure 2, Table 1). These evidences suggested that environment of high concentration NE or appropriate treatment time of NE induced proliferation of CT26 cells requiring of ART1. 
Table 1 Cell cycle distribution and proliferative indices (PI) of CT26 cells in eight groups were determined by flow cytometry $\mathbb{\chi} \pm S D \otimes$

\begin{tabular}{|c|c|c|c|c|}
\hline \multirow[t]{2}{*}{ Groups } & \multicolumn{3}{|c|}{ Cell cycle distribution } & \multirow{2}{*}{$\begin{array}{l}\mathrm{Pl}(\%) \\
(\mathrm{G} 2+\mathrm{S}) /(\mathrm{G} 1+\mathrm{S}+\mathrm{G} 2)\end{array}$} \\
\hline & G1 phase & S phase & G2 phase & \\
\hline GFP-ART1 +NE & $34.75 \pm 0.78^{\star \star \# \# \boldsymbol{\Delta} \Delta}$ & $51.96 \pm 0.52 * \# \# \mathbf{\Lambda} \Delta$ & $13.30 \pm 0.57$ & $65.25 \pm 0.78 * \star \# \# \boldsymbol{\Delta \Lambda}$ \\
\hline Un-transfection +NE & $45.25 \pm 0.58 * \star$ & $42.45 \pm 1.88^{*}$ & $12.30 \pm 1.46$ & $54.75 \pm 0.58 * \star$ \\
\hline GFP-Vector +NE & $45.55 \pm 0.50 * *$ & $41.45 \pm 1.33$ & $13.00 \pm 1.06$ & $54.45 \pm 0.50 \star \star$ \\
\hline GFP-shART1+NE & $56.47 \pm 1.17^{\# \#}$ & $31.08 \pm 1.62^{\# \#}$ & $12.45 \pm 0.77$ & $43.53 \pm 1.17^{\# \#}$ \\
\hline GFP-ART1 & $40.52 \pm 0.57^{\# \# \mathbf{\Lambda} \boldsymbol{\Delta}}$ & $47.84 \pm 1.30^{\# \# \mathbf{\Lambda} \boldsymbol{\Lambda}}$ & $11.64 \pm 1.17$ & $59.48 \pm 0.57^{\# \# \mathbf{\Lambda} \Delta}$ \\
\hline Un-transfection & $51.05 \pm 0.63$ & $34.83 \pm 1.86$ & $14.12 \pm 1.54$ & $48.95 \pm 0.63$ \\
\hline GFP-Vector & $50.97 \pm 0.7$ & $37.35 \pm 1.77$ & $11.69 \pm 1.52$ & $49.03 \pm 0.70$ \\
\hline GFP-shART1 & $57.65 \pm 1.53^{\# \#}$ & $29.85 \pm 1.51^{\#}$ & $12.50 \pm 1.24$ & $42.36 \pm 1.53^{\# \#}$ \\
\hline \multicolumn{5}{|c|}{ 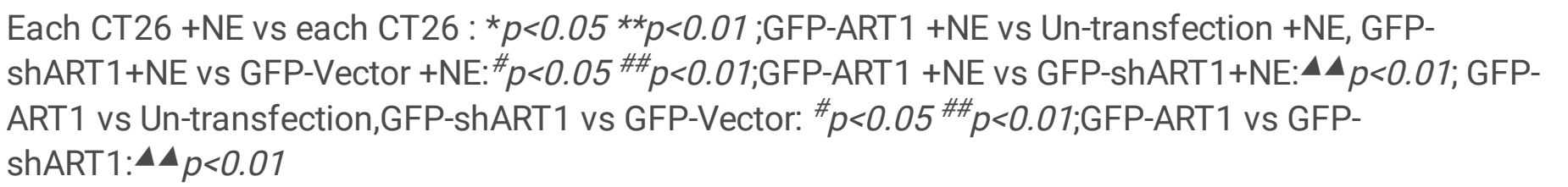 } \\
\hline
\end{tabular}

Besides, on same concentration or at same treatment time of NE, proliferation of CT26 cells presented highest in GFP-ART1 group and lowest in GFP-ShART1 groupDTable 2, 30,demonstrated that ART1 boosted proliferation of CT26 cells as well. 
Table 2 Influence of ART1 on the cell proliferation activity of mouse colon carcinoma CT26 cells treated by NE with difference levels $₫ \bar{\chi} \pm S D \bigotimes$

\begin{tabular}{|c|c|c|c|c|}
\hline NE & GFP-ART1 & Un-transfection & GFP-vector & GFP-shART1 \\
\hline \multicolumn{5}{|c|}{ Ummol/L } \\
\hline 0.2 & $107.79 \pm 9.56$ & $100.68 \pm 5.12$ & $103.28 \pm 3.68$ & $98.97 \pm 4.51$ \\
\hline 0.4 & $109.70 \pm 9.94$ & $103.59 \pm 7.20$ & $109.04 \pm 5.34$ & $92.41 \pm 4.26$ \\
\hline 0.6 & $113.69 \pm 8.23^{\# \#}$ & $111.80 \pm 6.71$ & $108.41 \pm 5.47$ & $89.44 \pm 3.64 *$ \\
\hline 0.8 & $126.36 \pm 8.32^{\# \#}$ & $111.43 \pm 6.55$ & $116.42 \pm 12.53$ & $89.27 \pm 4.86^{*}$ \\
\hline 1.0 & $134.16 \pm 6.53^{\# \#_{\star}}$ & $116.20 \pm 9.36$ & $118.21 \pm 7.33$ & $92.91 \pm 5.24^{\star}$ \\
\hline
\end{tabular}

Table 3 Influence of ART1 on the cell proliferation activity of mouse colon carcinoma CT26 cells treated by NE with difference times $\mathbb{\overline { \chi }} \pm \mathrm{SD} \rrbracket$

\begin{tabular}{|c|c|c|c|c|}
\hline $\begin{array}{l}\text { Time } \\
\text { (h) }\end{array}$ & GFP-ART1 & Un-transfection & GFP-vector & GFP-shART1 \\
\hline 12 & $108.12 \pm 2.99$ & $98.93 \pm 4.56$ & $102.88 \pm 3.44$ & $98.81 \pm 1.77$ \\
\hline 24 & $135.04 \pm 7.32^{\# \#_{\star \star}}$ & $109.80 \pm 3.15$ & $107.01 \pm 3.71$ & $95.97 \pm 3.02$ \\
\hline 36 & $146.55 \pm 8.40^{\# \# \#_{\star}}$ & $129.82 \pm 4.39$ & $129.78 \pm 4.03$ & $94.41 \pm 2.72^{\star \star}$ \\
\hline 48 & $140.13 \pm 6.77^{\# \# \#_{\star \star \star}}$ & $115.72 \pm 3.77$ & $120.24 \pm 7.61$ & $95.56 \pm 2.78 * *$ \\
\hline \multicolumn{5}{|c|}{ GFP-ART1 vs GFP-shART1: ${ }^{\#} p<0.01$; } \\
\hline \multicolumn{5}{|c|}{ GFP-ART1 vs un-transfection, GFP-vector vs GFP-shART1:* $p<0.05,{ }^{* \star} p<0.01$} \\
\hline
\end{tabular}

\section{Establishment of Animal model of diabetes}

A diabetic Balb/c mouse model was established by feeding with high fat diet and $1 \%$ STZ intraperitoneal injection. Blood test showed significantly higher glucose concentration, insulin levels and NE level of diabetic mice than normal fed mice, besides, higher weight was detected in diabetic mice (Figure 3, Table 4), indicating diabetic model of Balb/c mice was successfully established. 
Table 4 The changes of body weight in mice were established after transplantation of tumor model $\nabla \bar{\chi} \pm S D \square$

\begin{tabular}{|c|c|c|}
\hline & CRCD weight loss $₫ g \rrbracket$ & CRCO weight loss $₫ \mathrm{~g} \rrbracket$ \\
\hline GFP-ART1 & $8.54 \pm 0.33^{* \star \# \boldsymbol{\Delta} \boldsymbol{\Delta}}$ & $6.37 \pm 0.32^{\# \# \mathbf{\Lambda} \Lambda}$ \\
\hline Un-transfection & $8.16 \pm 0.41^{\star \star}$ & $5.27 \pm 0.61$ \\
\hline GFP-vector & $7.94 \pm 0.38$ ** & $5.64 \pm 0.47$ \\
\hline GFP-shART1 & $7.4 \pm 0.38 * \star \#$ & $4.82 \pm 0.55^{\# \#}$ \\
\hline
\end{tabular}

CRCD vs CRCO in different ART1 expression level : * $p<0.01$;

CRCD group: GFP-ART1 vs Un-transfection, GFP-shART1 vs GFP-Vector , ${ }^{\#} p<0.05{ }^{\# \#} p<0.01 ;$ GFP-ART1 vs GFP-ShART1: $\triangle 4 p<0.01$;

CRCO group: GFP-ART1 vs Un-transfection, GFP-shART1 vs GFP-Vector , ${ }^{\#} p<0.05{ }^{\# \#} p<0.01 ;$ GFP-ART1 vs GFP-shART1: $\triangle 4 p<0.01$;

\section{ART1 impacted growth of transplant tumor and survival time in diabetic or non-diabetic mice}

Diabetic mice were inoculated subcutaneously with mice colon cancer CT26 cells into right axillary fossa. The results showed that, after inoculated with the same ART1 expression level CT26 cells, diabetic mice lost more weight than non-diabetic mice $(p<0.01)$, although absolute value of body weight was still higher in CRCD group than CRCO group $\varangle 21.82 \pm 1.64$ vs $21.04 \pm 1.08, p<0.05 \rrbracket$, besides, the volume and weight of transplanted tumors of CRCD group were larger than CRCO group $(p<0.05)$. On the other hand, inoculated with different ART1 expression level of CT26 cells, body weight loss was the most $(8.54+0.33 \mathrm{~g})$ and tumor was the largest and the heaviest in mice injected with high ART1 expressing CT26 cells $₫ p<0.01 \rrbracket$, but body weight loss was the least $(4.82+0.55 \mathrm{~g})$ and the transplanted tumor was the smallest and lightest in mice injected with ATR1 silenced CT26 cells (Figure 4, 5, Table. 5,6). 
Table 5 Effect of ART1 expression on weight situation of transplanted tumors of Balb/C mouse $\mathbb{X} \pm$ SD $\rrbracket$

\begin{tabular}{|c|c|c|}
\hline Group & $\begin{array}{l}\text { CRCD } \\
\text { weight (g) }\end{array}$ & $\begin{array}{l}\text { CRCO『g囚 } \\
\text { weight (g) }\end{array}$ \\
\hline GFP-ART1 & $6.85 \pm 0.37 \star \star \# \# \mathbf{\Lambda} \mathbf{\Delta}$ & $3.44 \pm 0.65^{\# \# \mathbf{\Delta} \mathbf{\Delta}}$ \\
\hline Un-transtection & $3.3 \pm 0.28 * \star$ & $1.89 \pm 0.29$ \\
\hline GFP-vector & $3.7 \pm 0.47 \star \star$ & $1.77 \pm 0.19$ \\
\hline GFP-shART1 & $2.17 \pm 0.26^{\star \star \# \#}$ & $0.6 \pm 0.19^{\#}$ \\
\hline
\end{tabular}

CRCD vs CRCO in different ART1 expression level : $* \star p<0.01$;

CRCD group: GFP-ART1 vs Un-transfection, GFP-shART1 vs GFP-Vector , ${ }^{\#} p<0.05{ }^{\# \#} p<0.01 ;$ GFP-ART1 vs

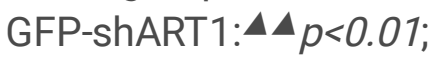

CRCO group: GFP-ART1 vs Un-transfection, GFP-shART1 vs GFP-Vector, ${ }^{\#} p<0.05^{\# \#} p<0.01$;GFP-ART1 vs GFP-ShART1: ${ }^{4} p<0.01$

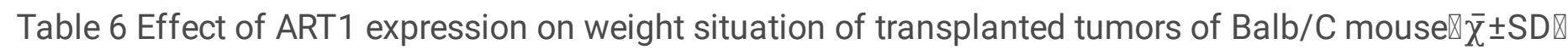
Group CRCD $\mathrm{CRCO} \rrbracket \mathrm{g} \rrbracket$

weight (g) weight (g)

GFP-ART1

6.85 $0.37 * * \# \# \boldsymbol{\Lambda \Lambda}$

$3.44 \pm 0.65^{\# \# \mathbf{\Delta} \boldsymbol{\Delta}}$

Un-transtection

$3.3 \pm 0.28$ **

$1.89 \pm 0.29$

GFP-vector

$3.7 \pm 0.47^{\star *}$

$1.77 \pm 0.19$

GFP-shART1

$2.17 \pm 0.26^{\star \star \# \# ~}$

$0.6 \pm 0.19^{\#}$

CRCD vs CRCO in different ART1 expression level: ${ }^{*} p<0.01$;

CRCD group: GFP-ART1 vs Un-transfection, GFP-shART1 vs GFP-Vector, ${ }^{\#} p<0.05,{ }^{\# \#} p<0.01$; GFP-ART1 vs GFP-ShART1: $4 \mathbf{4} p<0.01$

CRCO group: GFP-ART1 vs Un-transfection, GFP-shART1 vs GFP-Vector, ${ }^{\#} p<0.05^{\# \#} p<0.01 ;$ GFP-ART1 vs GFP-shART1: $4 \mathbf{4} p<0.01$;

We still investigated the impact of ART1 and diabetes on survival time of mice models of transplant tumor. The data demonstrated that after inoculated with the same ART1 expression level CT26 cells, the survival time of in CRCD group were shorter than $C R C O$ group $\mathbb{P}<0.05 \otimes$ (Figure 6). Furthermore, with different ART1 expression levels CT26 cells injection, survival time of both CRCD and CRCO groups was the shortest in 
mice injected with high ART1 expressing CT26 cells and longest in mice injected with ATR1 silenced CT26 cells $₫ p<0.01 \rrbracket$ (Table. 7).

\begin{tabular}{|c|c|c|}
\hline \multirow[t]{2}{*}{ Group } & CRCD & $\mathrm{CRCO} \otimes \mathrm{g} \rrbracket$ \\
\hline & Survial time (day) & Survial time (day) \\
\hline GFP-ART1 & $15.67 \pm 1.26^{\# \# \mathbf{\Delta} \boldsymbol{\Delta}}$ & $18.5 \pm 0.56^{\# \# \mathbf{\Lambda \Lambda}}$ \\
\hline Un-transtection & $24.17 \pm 0.98$ & $27.5 \pm 1.2$ \\
\hline GFP-vector & $23.83 \pm 1.62$ & $27.17 \pm 1.14$ \\
\hline GFP-shART1 & $34.17 \pm 1.83^{\star \# \#}$ & $39.5 \pm 1.36^{\# \#}$ \\
\hline \multicolumn{3}{|c|}{ CRCD vs CRCO in different ART1 expression level: ${ }^{*} p<0.05$} \\
\hline \multicolumn{3}{|c|}{$\begin{array}{l}\text { CRCD group: GFP-ART1 vs Un-transfection, GFP-shART1 vs GFP-Vector, }{ }^{\# \#} p<0.01 ; \text { GFP-ART1 vs GFP- } \\
\text { shART1: } \boldsymbol{\Lambda 4}_{p<0.01 ;}\end{array}$} \\
\hline \multicolumn{3}{|c|}{$\begin{array}{l}\text { CRCO group: GFP-ART1 vs Un-transfection, GFP-shART1 vs GFP-Vector, }{ }^{\# \#} p<0.01 ; \text { GFP-ART1 vs GFP- } \\
\text { shART1: } \boldsymbol{\Delta \Lambda}_{p<0.01 ;}\end{array}$} \\
\hline
\end{tabular}

\section{Renal denervation reduced level of blood glucose and growth of xenograft with high ART1 in CRCD mice}

We established animal models of renal denervation successfully since NE level of kidney and plasma in operated group (LRD) were decreased over 10\% $[28,29](p<0.01)$. Then, we measured blood glucose and plasma insulin levels of each group, also volume and weight of transplanted tumor. The result showed lower value of blood glucose and plasma insulin as well as smaller and lighter tumor of operated group, compared with the sham-operated group (LSO) or non-operated group $(p<0.01)$, while no significant change was observed between non-operated group and LSO group $\mathbb{P}>0.05 \llbracket$ (Figure 7, Table. 8, 9). 


\begin{tabular}{|c|c|c|c|c|}
\hline \multicolumn{5}{|c|}{ Table 8 effect of renal denervation on biochemical characteristics in three groups $₫ \bar{\chi} \pm S D \otimes$} \\
\hline Group & $\begin{array}{l}\text { Kidney NE } \\
(\mathrm{ng} / \mathrm{g})\end{array}$ & $\begin{array}{l}\text { Plasma NE } \\
(\mathrm{pg} / \mathrm{ml})\end{array}$ & $\begin{array}{l}\text { Glucose } \\
(\mathrm{mmol} / \mathrm{l})\end{array}$ & $\begin{array}{l}\text { Fins } \\
(\mathrm{pg} / \mathrm{ml})\end{array}$ \\
\hline non-operated group & $499.96 \pm 14.83^{* *}$ & $466.06 \pm 13.52 * \star$ & $14.08 \pm 0.19 * *$ & $175.57 \pm 3.72 * \star$ \\
\hline LSO & $510.74 \pm 15.4^{\star \star}$ & $452.37 \pm 7.01^{\star \star}$ & $13.7 \pm 0.15^{\star \star}$ & $178.94 \pm 2.7 \star \star$ \\
\hline LRD & $169.19 \pm 4.74$ & $211.73 \pm 2.61$ & $11.97 \pm 0.15$ & $130.12 \pm 3.88$ \\
\hline \multicolumn{5}{|c|}{ non-operated group vs LRD, LSO VS LRD $\nabla^{\star *} p<0.01$} \\
\hline \multicolumn{5}{|c|}{ Table 9 Effect of NE level on weight and volum situation of transplanted $\nabla \bar{\chi} \pm S D \rrbracket$} \\
\hline Group & \multicolumn{2}{|c|}{$\mathrm{V}(\mathrm{CM} 3)$} & \multicolumn{2}{|c|}{ Weight $\nabla \mathbf{g} \otimes$} \\
\hline non-operated group & \multicolumn{2}{|c|}{$2.08 \pm 0.5^{\star \star}$} & \multicolumn{2}{|c|}{$3.73 \pm 0.35^{\star \star}$} \\
\hline LSO & \multicolumn{2}{|c|}{$2.1 \pm 0.5^{\star \star}$} & \multicolumn{2}{|c|}{$3.75 \pm 0.39 * \star$} \\
\hline LRD & \multicolumn{2}{|c|}{$0.56 \pm 0.19$} & \multicolumn{2}{|c|}{$2.1 \pm 0.36$} \\
\hline \multicolumn{5}{|c|}{ non-surgery group vs LRD,LSO VS LRD $\rrbracket^{* *} p<0.01$} \\
\hline
\end{tabular}

\section{ART1 was positive associated with expression of p-AKT, mTOR, STAT3, cyclinD1 and c-myc in CT26 cells induced by high NE}

Western blot was used to detect protein expression level in different ART1 level CT26 cells with high NE. Result showed that GFP-ART1 CT26 cells presented highest expression level of ART1, p-AKT, mTOR, STAT3, CyclinD1 and c-myc $(P<0.01)$, while GFP-shART1 CT26 cells presented lowest expression level of these protein $(P<0.01)$, suggesting ART1 contributed to up-regulate $p-A K T$, mTOR, STAT3, CyclinD1 and c-myc with high NE (Figure 8).

\section{Expression pattern of ART1, p-AKT, mTOR, STAT3 in transplanted tumor of group of CRCD and CRCO mice and alteration after renal denervation performed on CRCD group}

Transplanted tumors of CRCD mice and CRCO mice were digested and detected by western blot. The expression of ART1, mTOR and STAT3 in CRCD group was significantly higher than that in CRCO group $(p<0.01)$, and there was no significant difference in the expression of AKT $(p>0.05)$, but the expression of PAKT was significantly higher for CRCD group than CRCO group ( $p<0.01$ ) (Figure 9). In vivo data also illustrated that high-NE environment boosted expression of ATR1, as well as P-AKT, mTOR and STAT3.

To discuss effect of NE on ART1-depended proliferation of CT26 cells, GFP-ART1 CT26 cells were inoculated in non-surgery group, LSO group (sham operation) and LRD group (renal denervation), transplanted tumors were digested and detected by western blot. The result showed that no significant difference of ART1 and AKT protein expression in these three groups ( $P>0.05)$, but expression of P-AKT $(p<0.01), m T O R \rrbracket p<0.05 \rrbracket$ and STAT3\p<0.05》 protein decreased obviously in group LRD (Figure 10). This result demonstrated after LRD performed, expression of P-AKT, MTOR and STAT3 was decreased 
consistently, however, interestingly, ART1 and AKT was not decreased, suggesting that expression of ART1 was not depended on NE, however, NE indeed impacted expression of proliferation-relative proteins.

\section{Discussion}

T2DM is a common comorbidity in colorectal cancer patients, besides, it is considered as a risk factor for this cancer and a prognostic factor for adverse survival outcomes as well [32]. However, the molecular mechanism of this connection remains elusive. T2DM is a metabolic disease characterized by insulin resistance, hyperinsulinemia, chronic activation of the sympathetic nervous system (SNS), increased circulating NE levels, and a high NE status $[7,8,9,10]$. It was also reported that increase of NE level, possibly through beta-adrenergic receptor signaling promoting colon cancer liver metastasis [33]. Besides, large case-control studies had also found that long-term use of norepinephrine antagonists or beta-receptor blocking agent drug could reduce the risk of malignant tumors including colorectal cancer $[16,17,34]$. Therefore, high level of NE seemed like not only related with T2DM but also with CRC development.

In this study, we found that ART1 was required in proliferation of colorectal cancer cell in high-NE environment accompanied with diabetes. Our further research revealed that ART1 activated the AKT-mTOR pathway, resulting in increased STAT3 phosphorylation and ultimately promoting Cyclin D1 and c-myc expression and cell proliferation.

Our previous studies $[20,21,22,23]$ showed high expression of ART1 boosted malignant biological behavior of CRC, besides, ADP-ribosylation was proved to impact glucose metabolism in several pathway [35]. However, there is no research of effect of ART1 on colorectal cancer associated with diabetes mellitus. Therefore, ART1 expression changes in colorectal cancer with type T2DM were discussed in this study. Consistent with our previous study, in spite of normal or high fatty diet, higher expression of ART1 was observed prefer in mice with lymph node metastasis than mice without metastasis, hinting ART1 related to malignant behavior of CRC. More importantly, result showed higher expression of ART1 after fed with high fatty diet rather than fed with normal diet. These evidences suggested that ART1 related to CRC-associated glucose metabolism disorders, but the mechanism of the effect remains to be further studied.

On the other hand, in vivo experimentation showed that diabetes accompany was a positive factor for growth of xenograft when ART1 at same level, while ART1 accelerated growth of xenograft and shortened survival time of diabetic and non-diabetic mouse models. Namely, both diabetes and ART1 encouraged growth of xenograft, however, when ART1 was silenced, difference was still detected between diabetic and non-diabetic mouse models, suggested that diabetes-accelerated growth of xenograft was not totally depend on ART1.

Furthermore, in vitro study showed that with increase of NE concentration and induction time, ART1-high CT26 cells presented consistent increase of proliferation, but no obvious change was detected in ART1silenced CT26 cells with increase of NE concentration and induction time. These illuminated that NE promoted proliferation of colorectal cancer CT26 cells depending on ART1. Based on what we found, it was concluded that, due to complicate factors in vivo co-effecting proliferation of cancer, although diabetes- 
accelerated growth of xenograft was not totally depend on ART1, NE promoting proliferation of colorectal cancer cells depended on ART1.

Phosphorylated STAT3 is linked to the activation of Akt/mTOR, and this pathway is involved in cell proliferation and cell growth. Result of both in vitro and in vivo experiments showed that expression of ART1 was positive associated with expression of $p-A K T$, mTOR and STAT3, rather than AKT, with high NE environment. After LRD reducing blood level of NE, expression of p-AKT, mTOR and STAT3 protein was decreased obviously, but the expression of ART1 and AKT protein in transplanted tumor had no obvious change, besides, the volume and weight of the transplanted tumor decreased significantly, clarified that reduce of NE level was an effective strategy for inhibition of xenograft growth. Consistent with our result, Lima-Seolin et al. found an increase in the activity of AKT/mTOR/STAT3 signaling pathway in the NE condition as well[36], our results suggested that NE was not required for expression of ART1, but was required for ART1-induced activation of AKT/mTOR/STAT3 signaling pathway.

Since STAT3 could increase transcription of Cyclin, D1 and c-myc, and promoted the proliferation of cells indefinitely, we further investigated the expression of Cyclin, D1, and c-myc proteins. The results indicated that expression of ART1 up-regulated the expression of CyclinD1 and c-myc proteins in the condition of high NE. Thus, combining previous results, we conjectured that ART1 could up-regulate expression of CyclinD1 and c-myc proteins by activating the AKT/mTOR/STAT3 signal pathway with high NE, and promote the proliferation and growth of CT26 cells.

\section{Conclusion}

In summary, this study proposed a hypothesis that ART1-induced activation of AKT/mTOR/STAT3 pathway and promoted the proliferation of colorectal cancer by up-regulating expression of Cyclin D1, c-myc protein subsequently, requiring high-NE environment. Although, this study has certain limitation, the further molecular mechanism needs to be proved, might provide an explanation for T2DM (high NE status) with poorer prognosis of $\mathrm{CRC}$, moreover, give a rise to ART1 could be a therapy target for T2DM-associated colorectal cancer patients.

\section{Declarations}

\section{Availability of data and materials}

Not applicable.

\section{Ethics approval}

All animal experiments were approved and performed in accordance with guidelines and regulations of the Institutional Animal Care and The Ethics Committee of Chongqing Medical University (Reference No:0002675).

\section{Consent for publication}


Not applicable.

\section{Competing interests}

The authors declare that they have no competing interests.

\section{Funding}

This research was supported by Science and Technology Research Foundation of Chongqing Municipal Education Commission (KJQN201800435) and Innovation Project of Graduate Student in Chongqing (CYB19160)

\section{Authors' contributions}

CWW established the animal modules and extracted sample from mice. YYP and DJL performed western blot for cells and tissue samples. LM participated in animal experiments and was one of major contributors in writing the manuscript. TY and ZSX performed CT26 cells survival assay and flow cytometry. GHJ and LQS participated in animal experiments. WYL analyzed statistic data and was another major contributor in writing the manuscript. All authors read and approved the final manuscript.

\section{Acknowledgements}

The authors thank all current and past members of Department of Pathology, Chongqing Medical University.

\section{References}

[1] Mills KT, Bellows CF, Hoffman AE et al. Diabetes mellitus and colorectal cancer prognosis: a metaanalysis. Dis Colon Rectum. 2013;56:1304-19.

[2] González N, Prieto I, Del Puerto-Nevado L, et al. 2017 update on the relationship between diabetes and colorectal cancer: epidemiology, potential molecular mechanisms and therapeutic implications. Oncotarget. 2017;8:18456-85.

[3] Iswarya SK, Premarajian KC,Kar SS, et al. Risk factors for the development

of colorectal carcinoma: A case control study from South India. World J Gastrointest Oncol. 2016;8:207-14.

[4] Robert J, Eleanor M, Stephen G, et a1. Impact of type 2 diabetes mellitus on sympathetic neural mechanisms in hypertension. Circulation. 2003;108:3097 -101.

[5] Bouhon AJ, Vinik Al, Arezzo JC, et a1. Diabetic neuropathies:a statement by the American Diabetes Association. Diabetes Care. 2005;28:956-62.

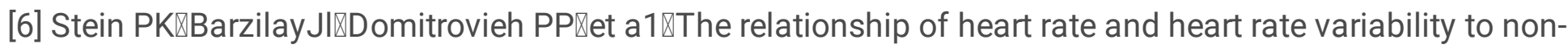
diabetic fasting glucose levels and the metabolic syndr- ome $\bigotimes$ The cardiovascular Health Study $₫$ Diabet Med. 2007;24:855-63凶 
[7] Huggett RJ, Scott EM, Gilbery SG, et al. Impact of type 2 diabetes mellitus on sympathetic nerural mechanisms in hypertension. Criculation. 2003;108: 3097 - 101.

[8] Mancia G, Bouspuet P, Elghozi JL, et al. The sympathetic nervous system and the metabolic syndrome. J Hypertens. 2007;25:909-20.

[9] Grassi G, Dell'Oro R, Quarti-Trevano F, et al. Neuroadrenergic and reflex abnor-

malities in patients with metabolic sysdrome. Diabetologia. 2005;48: 1359 -65.

[10] Huggett RJ, Burns J, Mackintosh AF, et al. Sympathetic neural activation in nondiabetic metabolic syndrome and its further augmentation by hypertension. Hypertension. 2004;44:847-52.

[11] Yang E V, Sood AK, Chen M,et al. Norepinephrine up-regulates the expression of vascular endothelial growth factor, matrix metalloproteinase (MMP)-2, and MMP-9 in nasopharyngeal carcinoma tumor cells. Cancer Res. 2006;66: $10357-64$.

[12] Sood AK, Bhatty R, Kam at AA, et al. Stress Hormone-mediated invasion of ovarian cancer Cells. Clin Cancer Res. 2006;12:369-75.

[13] Landen CN, Lin YG, Armaiz Pena GN, et al. Neuroendocrine modulation of signal transducer and activator of transcription-3 in ovarian cancer. Cancer Res. 2007;67:10389-96.

[14] Huang XY, Wang HC, Yuan Z, et al. Norepinephrine Stimulates Pancreatic Cancer Cell Proliferation, Migration and Invasion Via Beta-Adrenergic Receptor-Dependent Activation of P38/MAPK Pathway. Hepatogastroenterology. 2011;59:115-6.

[15] Deng GH, Liu J, Zhang J, et al. Exogenous norepinephrine attenuates the efficacy of sunitinib in a mouse cancer model. J Exp Clin Cancer Res. 2014;33:21.

[16] Friedman GD, Udaltsova N, Habel LA. Norepinephrine antagonists and cancer risk. Int J Cancer. 2011;128: 736-8.

[17] Fitzgerald PJ. Is norepinephrine an etiological factor in some types of cancer? Int J Cancer. 2009;124:257-63.

[18] Laing S, Unger M, Koch-Nolte F, et al. ADP-ribosylation of arginine. Amino acids. 2011;41:257-69.

[19] Okazaki IJ, Moss J. Mono-ADP-ribosylation: a reversible posttranslational modification of proteins. Adv Pharmacol. 1996;35:247-80.

[20] Xu JX, Xiong W, Zeng Z, et al. Effect of ART1 on the proliferation and migration of mouse colon carcinoma CT26 cells in vivo. Mol Med Rep. 2017;15:1222-8.

[21] Yang L, Xiao M, Li X, et al. Arginine ADP-ribosyltransferase 1 promotes angiogenesis in colorectal cancer via the PI3K/Akt pathway. Int J Mol Med. 2016;37:734-42. 
[22] Xiao M, Tang Y, Wang YL, et al. ART1 Silencing Enhances Apoptosis of Mouse CT26 Cells via the PI3K/Akt/NF-KB Pathway. Cell Physiol Biochem. 2013;32:1587-99.

[23] Tang Y, Wang YL, Yang L, et al. Inhibition of arginine ADP-ribosyltransferase 1 reduces the expression of poly(ADP-ribose) polymerase-1 in colon carcinoma. Int J Mol Med. 2013;32:130-6.

[24] Kuang J, Wang YL, Xiao M, et al. Synergistic effect of arginine-specific ADP-ribosyltransferase 1 and poly(ADP-ribose) polymerase-1 on apoptosis induced by cisplatin in CT26 cells. Oncol Rep. 2014;31:233543.

[25] Sun N, Yang G, Zhao H, et al. Multidose Streptozotocin Induction of Diabetes in BALB/c Mice Induces a Dominant Oxidative Macrophage and a Conversion of TH1 to TH2 Phenotypes During Disease Progression. Mediators inflamm. 2005;2005:202-9.

[26] G Luippold, M Beilharz , B Muhlbauer, et al. Chronic renal denervation prevents glomerular hyperfiltration in diabetic rats. Nephrol Dial Transplant. 2004;19: 342-7.

[27] LD Dias, KR Casali, NM Leguisamo, et al. Renal denervation in an animal model of diabetes and hypertension: Impact on the autonomic nervous system and nephropathy. Cardiovasc Diabetol. 2011;10:33.

[28] Chen W, Chang Y, He L, et al. Effect of renal sympathetic denervation on hepatic glucose metabolism and blood pressure in a rat model of insulin resistance. J Hypertens. 2016;34:2465-74.

[29] T Katayama, D Sueta, K Kataoka, et al. Long-Term Renal Denervation Normalizes Disrupted Blood Pressure Circadian Rhythm and Ameliorates Cardiovascular Injury in a Rat Model of Metabolic Syndrome. J Am Heart Assoc. 2013;2:e000197.

[30] Lee CK, Park KK, Lim SS, et al. Effects of the licorice extract against tumor growth and cisplatin-induced toxicity in a mouse xenograft model of colon cancer. Biol Pharm Bull. 2007;30:2191-5.

[31] Carlsson G, Gullberg B, Hafström L. Estimation of liver tumor volume using different formulas-an experimental study in rats. J Cancer Res Clin Oncol. 1983;105:20-3.

[32] Voutsadakis IA. Obesity and diabetes as prognostic factors in patients with colorectal cancer. Diabetes Metab Syndr. 2017;11 Suppl 1: S109-14.

[33] Zhao L, Xu J, Liang F, et al. Effect of Chronic Psychological Stress on Liver metastasis of Colon Cancer in Mice. PLoS One. 2015;10: e0139978.

[34] Jansen L, Below J, Chang-Claude J, et al. Beta blocker use and colorectal cancer risk: population-based case-control study. Cancer. 2012;118:3911-9.

[35] Hopp AK, Grüter P, Hottiger MO. Regulation of Glucose Metabolism by NAD+ and ADP-Ribosylation. Cells. 2019;8(8). 
[36] de Lima-Seolin BG, Nemec-Bakk A, Forsyth H, et al. Bucindolol Modulates Cardiac Remodeling by Attenuating Oxidative Stress in H9c2 Cardiac Cells Exposed to Norepinephrine. Oxid Med Cell Longev. 2019;2019:6325424.

\section{Figures}
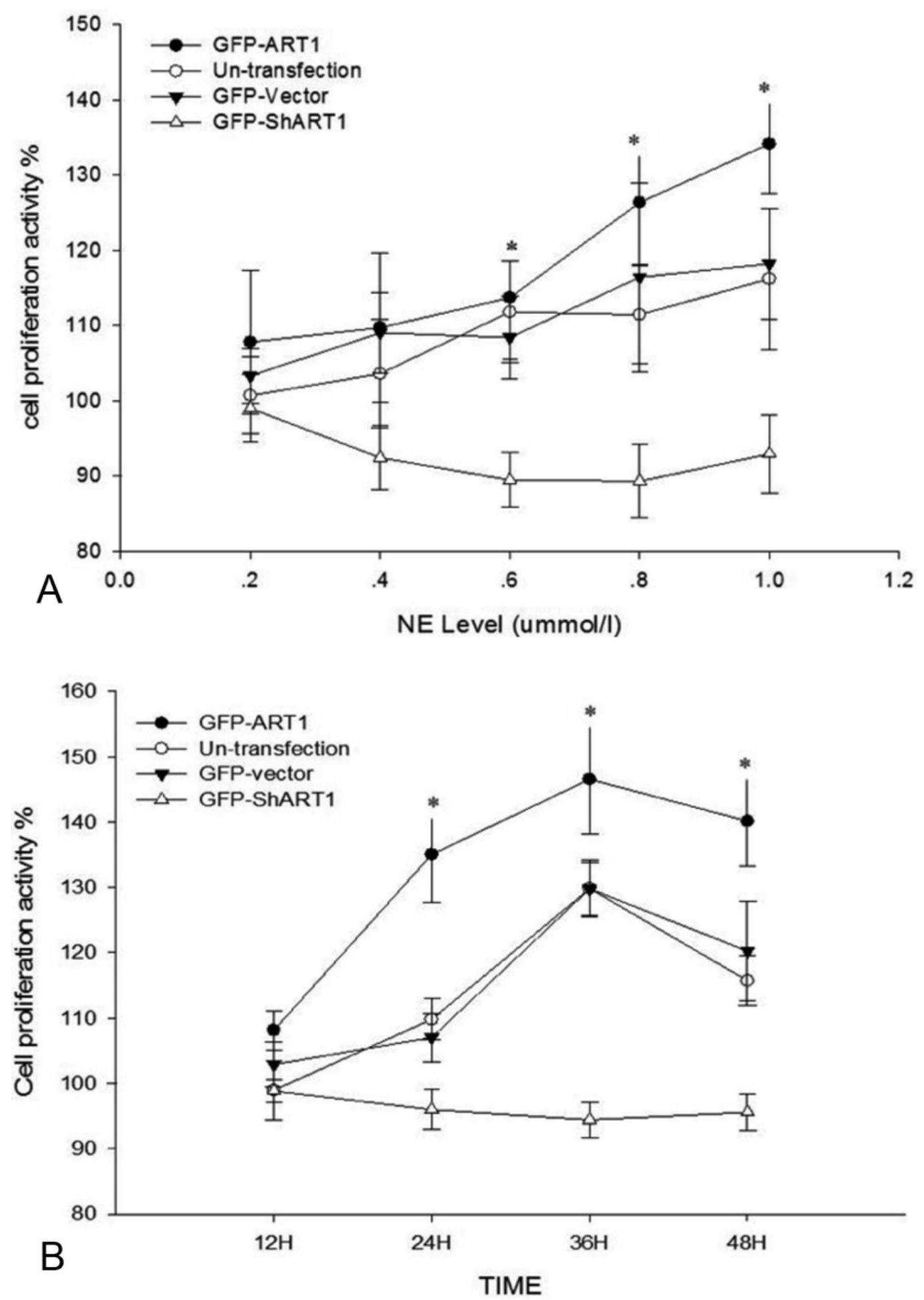

Figure 1 
Proliferation of variety ATR1 level of CT26 cells in environment with NE. A showed the proliferation of variety ATR1 level of CT26 cells treated with different concentration of NE; B showed the proliferation of variety ATR1 level of CT26 cells treated same concentration of NE with different time.
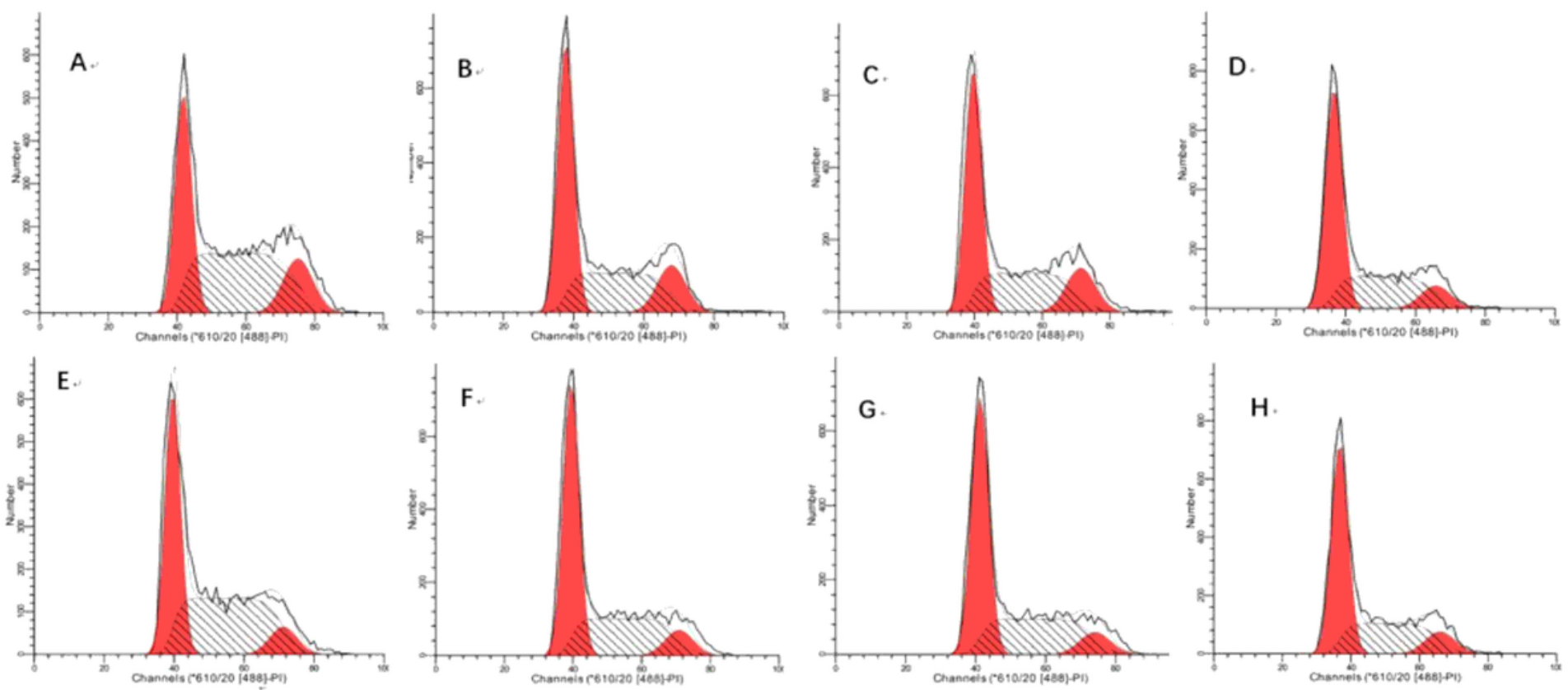

Figure 2

Cell cycle distributions of CT26 cells with different level ART1 treated with or without NE. A showed cell cycle distributions of GFP-ART1 CT26 with NE $(1 \mu \mathrm{mmol} / \mathrm{l})$ treated; B showed cell cycle distributions of untransfection of CT26 with NE $(1 \mu \mathrm{mmol} / \mathrm{I})$ treated; $\mathrm{C}$ showed cell cycle distributions of GFP-Vector CT26 with NE $(1 \mu \mathrm{mmol} / \mathrm{I})$ treated; D showed cell cycle distributions of GFP-shART1 CT26 with NE $(1 \mu \mathrm{mmol} / \mathrm{l})$ treated; E showed cell cycle distributions of GFP-ART1 CT26 without NE treated; F showed cell cycle distributions of untransfection of CT26 without NE treated; G showed cell cycle distributions of GFP-Vector CT26 without NE treated; $\mathrm{H}$ showed cell cycle distributions of GFP-shART1 CT26 without NE treated. 

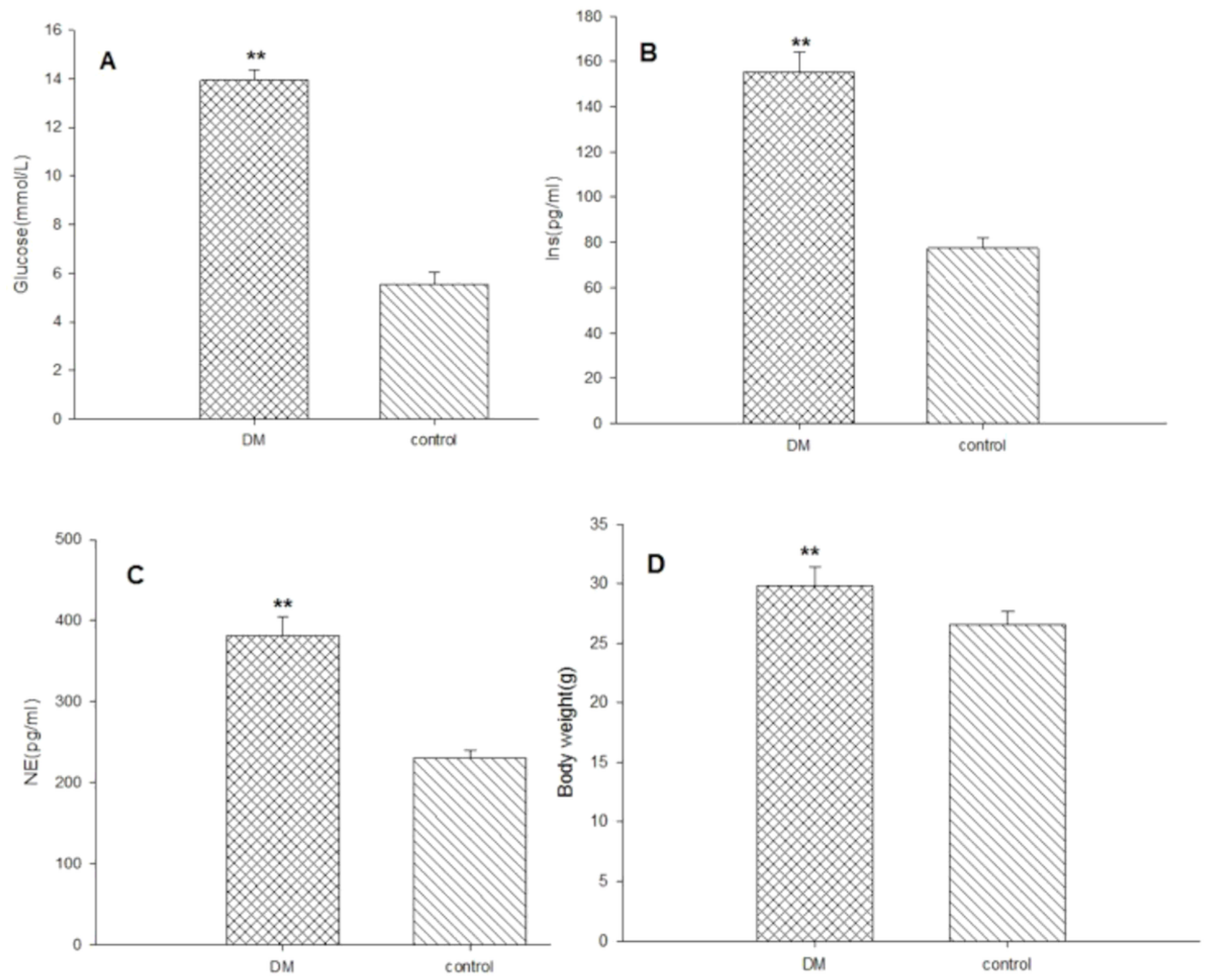

Figure 3

Metabolic index of DM mice and non-DM mice. $\left({ }^{\star *} \mathrm{P}<0.01\right)$ 

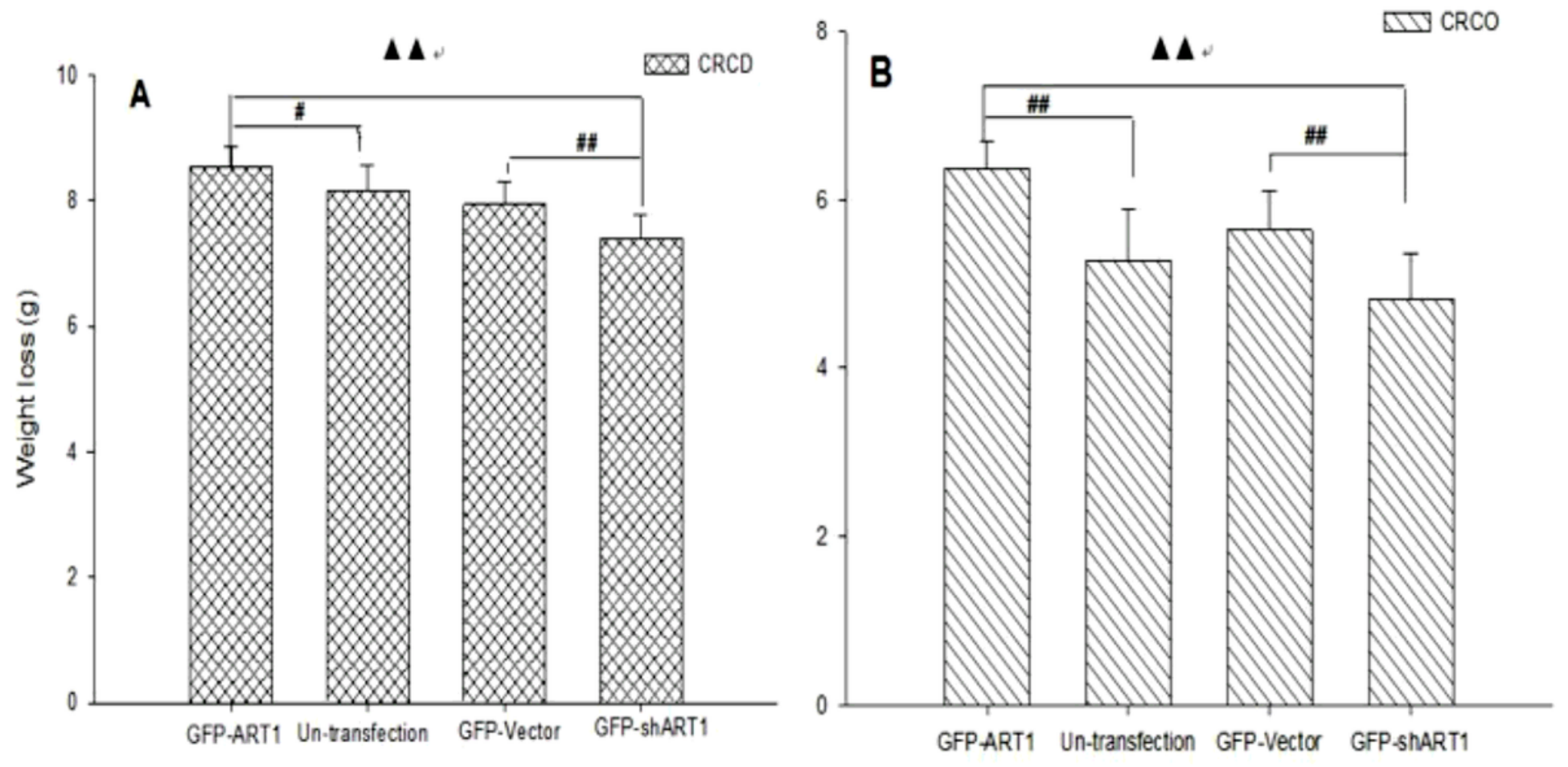

Figure 4

Weight loss of DM mice and non-DM mice transplanted with different ART1 level of CT26 cells. A showed result of DM mice transplanted with different ART1 level of CT26 cells; B showed result of non-DM mice transplanted with different ART1 level of CT26 cells (GFP-ART1 vs Un-transfection, GFP-shART1 vs GFPVector, \# $p<0.05 \# \# p<0.01 ; G F P-A R T 1$ vs GFP-shART1: $\mathbf{\Delta} \mathbf{\Delta} p<0.01)$. 


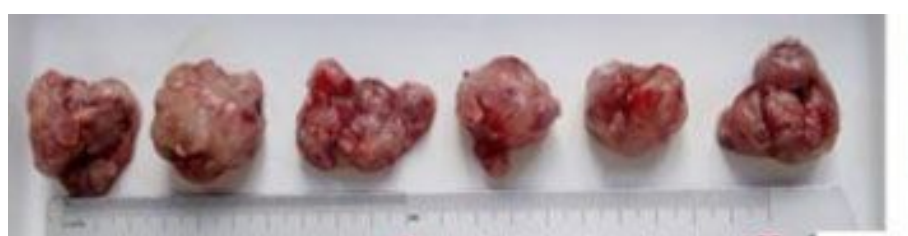

$=1 \quad 2 \quad 3 \quad 4 \quad 5 \quad 6 \quad 7 \quad 8 \quad 910 \quad 111213 \quad 14 \quad 1516 \quad 17 \quad 181920$

A.
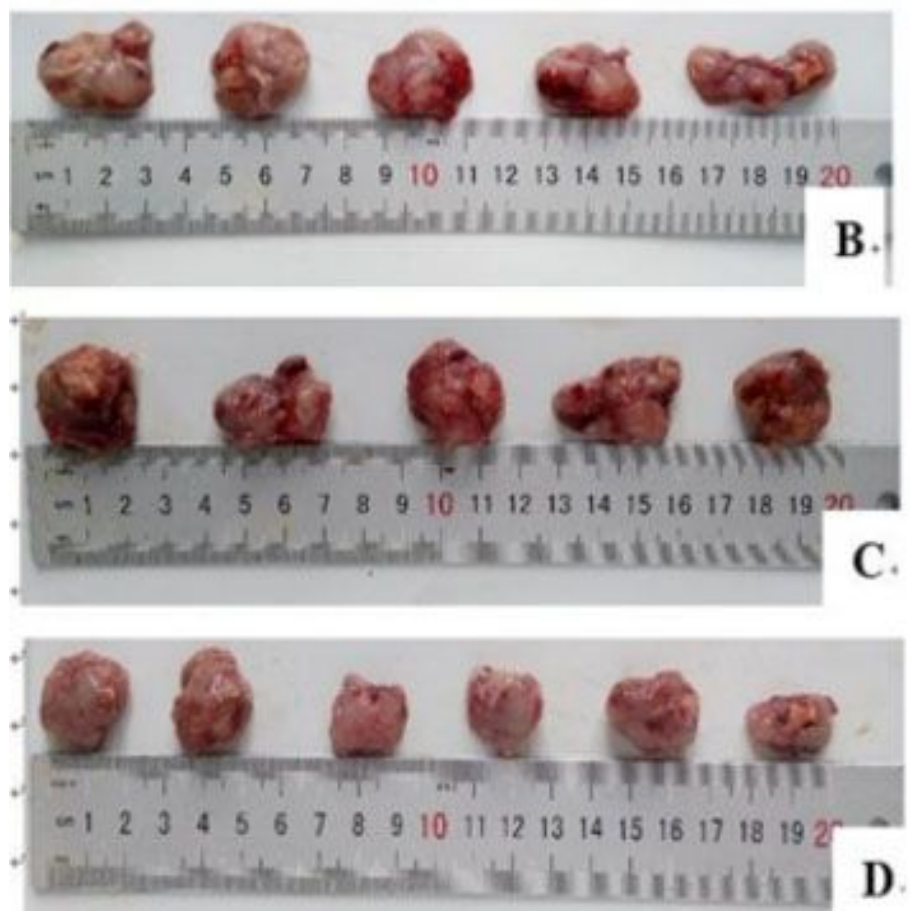
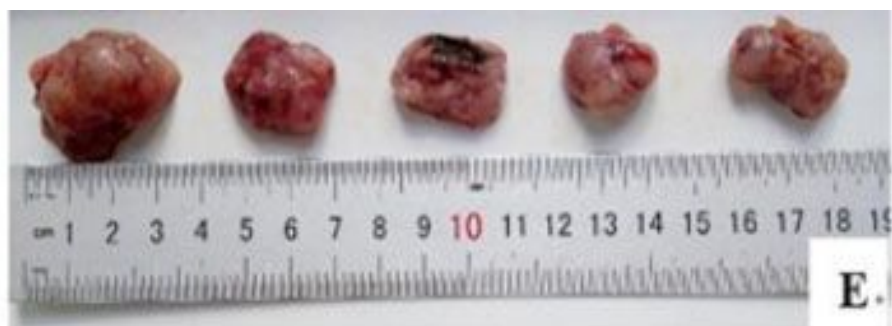

E.
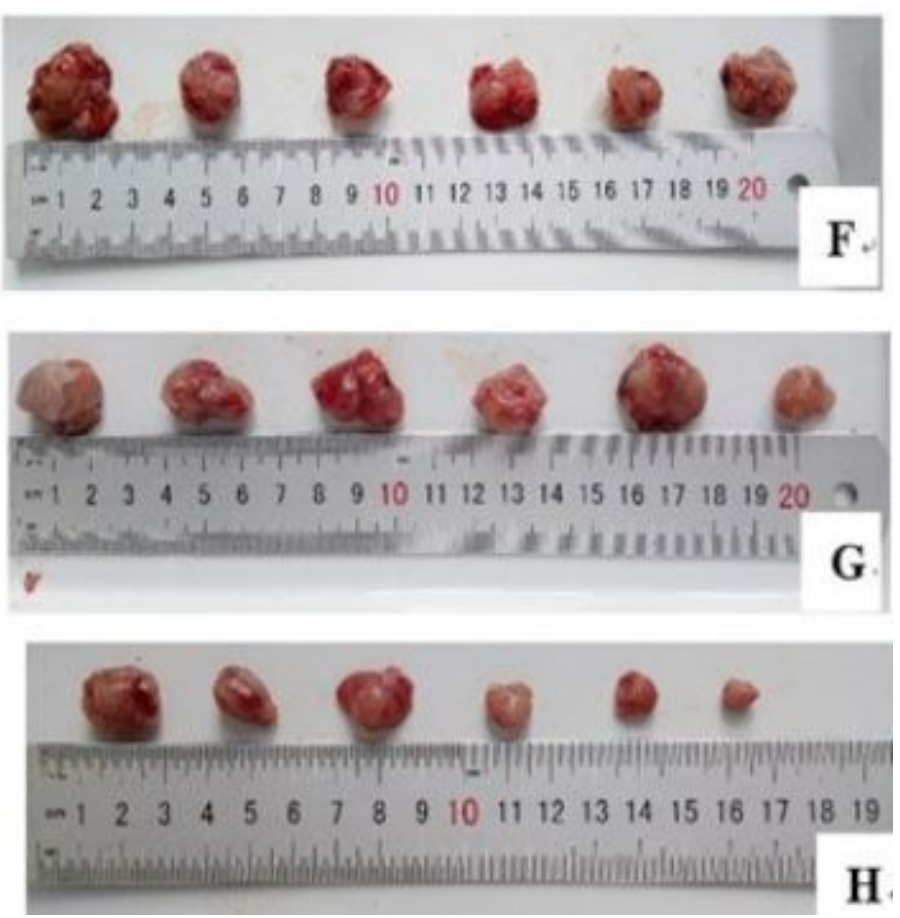

\section{Figure 5}

Tumor size of DM mice and non-DM mice transplanted with different ART1 level of CT26 cells. A showed tumors of DM mice transplanted with GFP-ART1 CT26; B s showed tumors of DM mice transplanted with un-transfection CT26; C showed tumors of DM mice transplanted with GFP-Vector CT26; D showed tumors of DM mice transplanted with GFP-shART1 CT26; E showed tumors of non-DM mice transplanted with GFPART1 CT26; $F$ showed tumors of non-DM mice transplanted with un-transfection CT26; $G$ showed tumors of non-DM mice transplanted with GFP-Vector CT26; $\mathrm{H}$ showed tumors of non-DM mice transplanted with GFPshART1 CT26. 


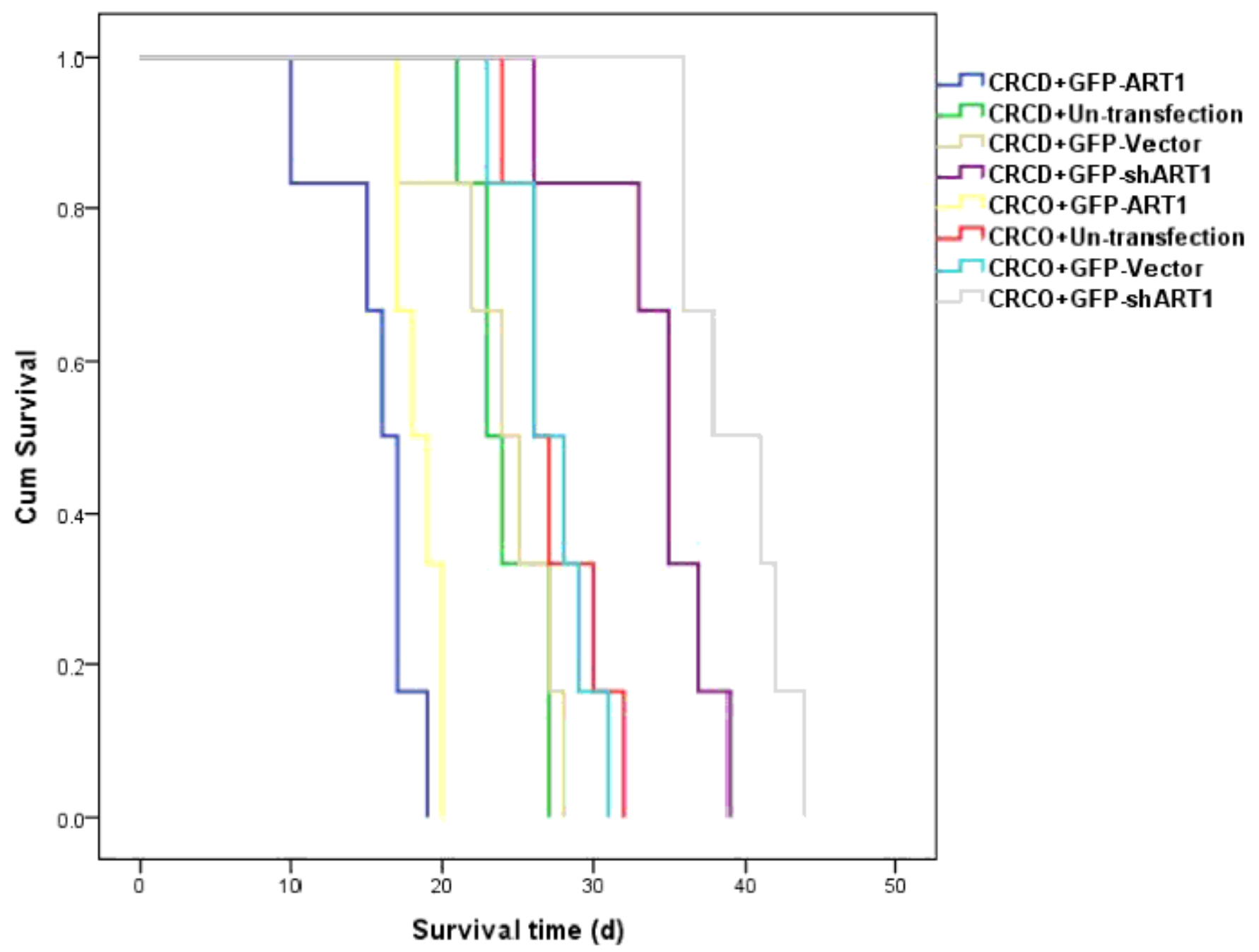

Figure 6

Survival time of DM mice and non-DM mice transplanted with different ART1 level of CT26 cells. 


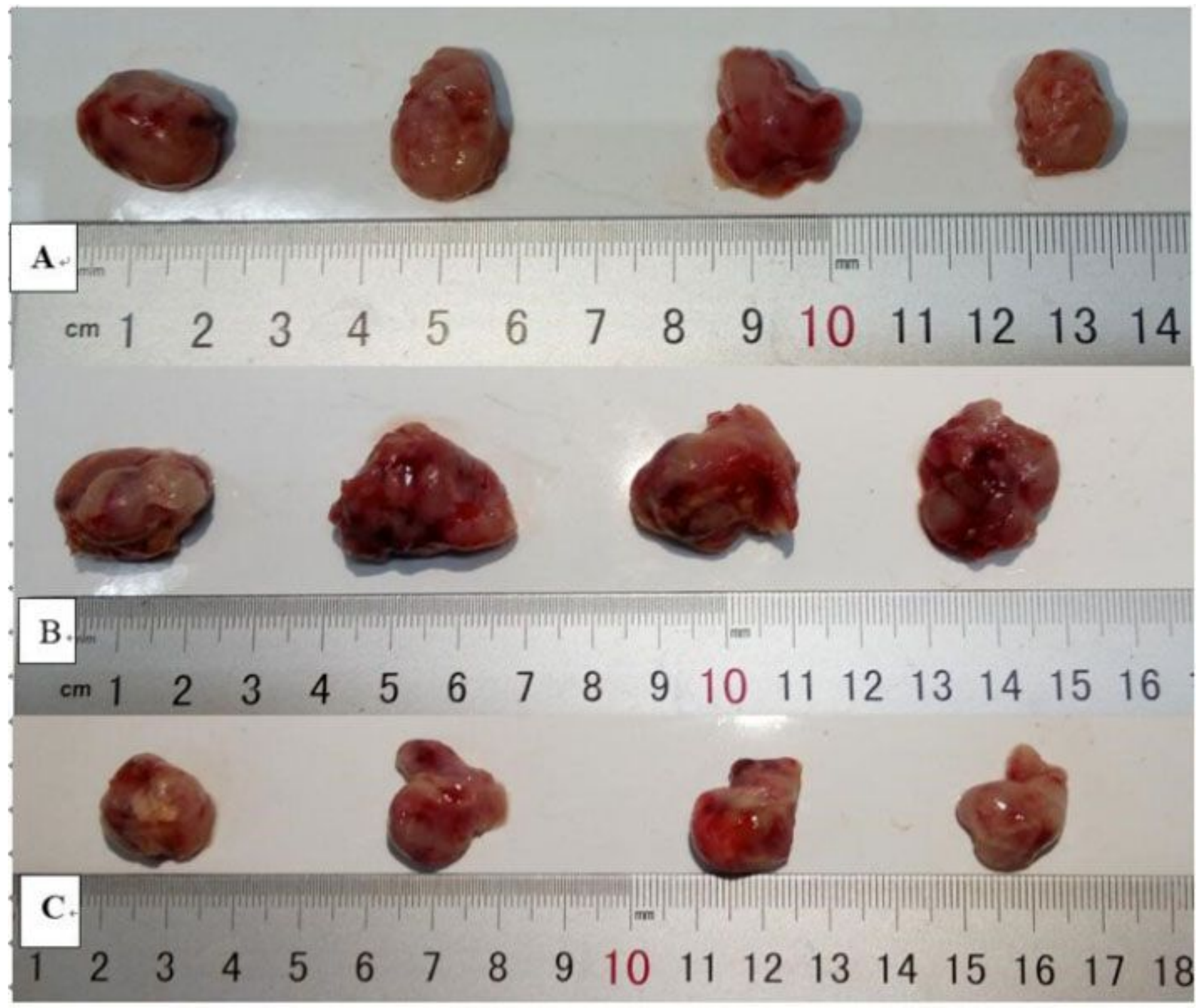

\section{Figure 7}

Tumor size of DM mice transplanted with high ART1 level of CT26 cells intervening in serum NE by surgery. A:GFP-ART1 group B:LSO group C:LRD group 

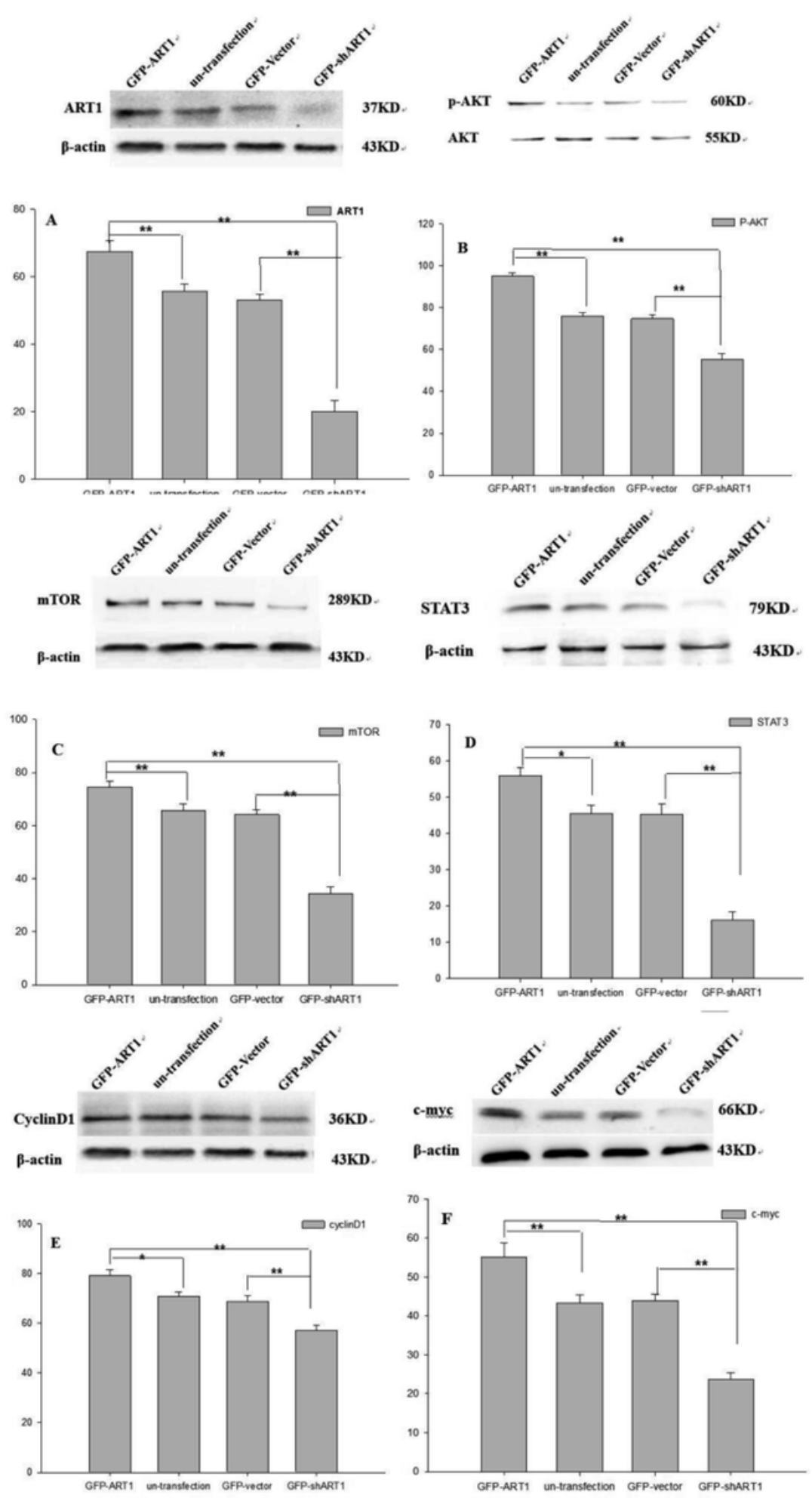

Figure 8

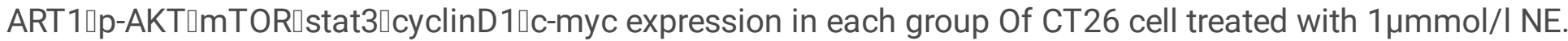

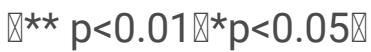


A. CRCD CRCO.

ART1

B-Actin

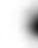

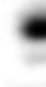

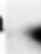

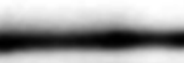

37KD.

43KD.
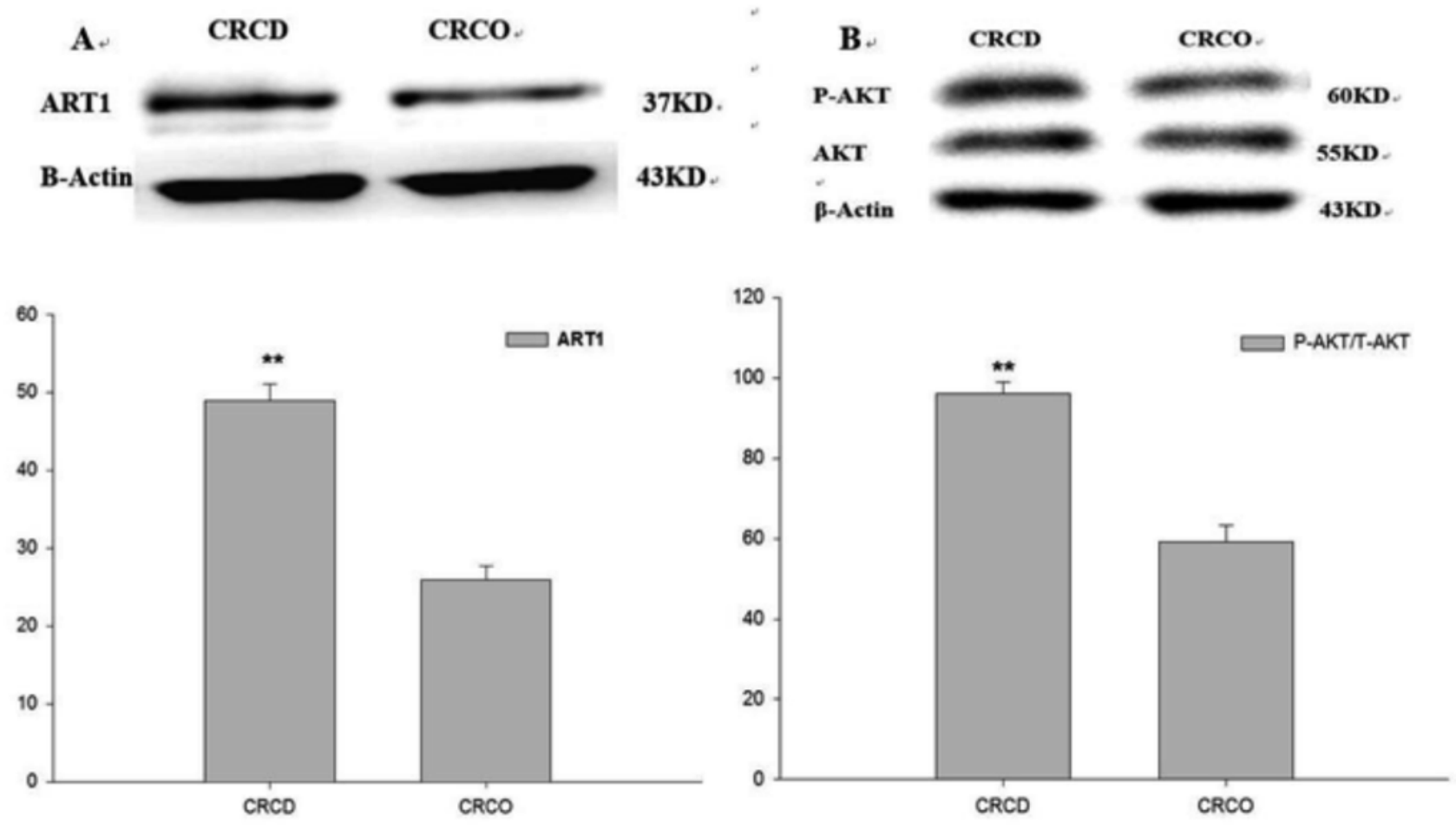

CRCD

CRCO.

\section{C. \\ MTor \\ - \\ $\beta$-actin}

-

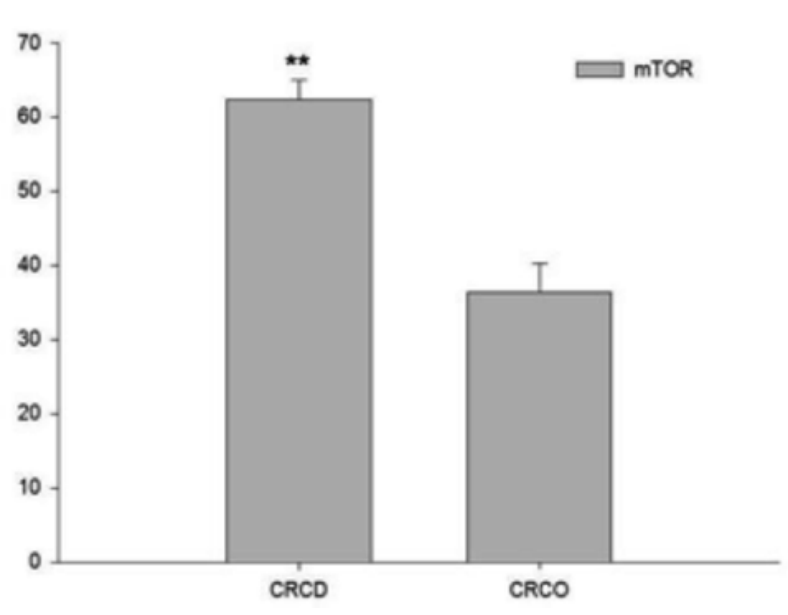

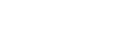

289kd.

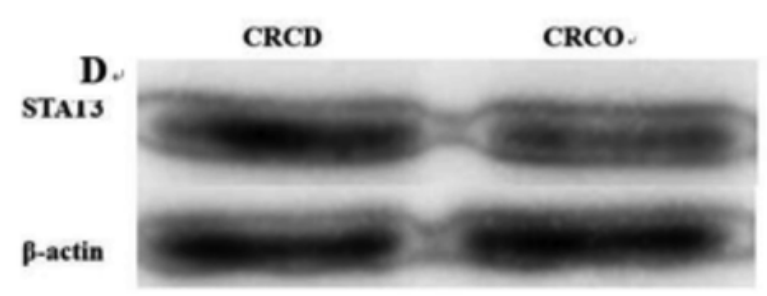

79 KD

$43 \mathrm{KD}$

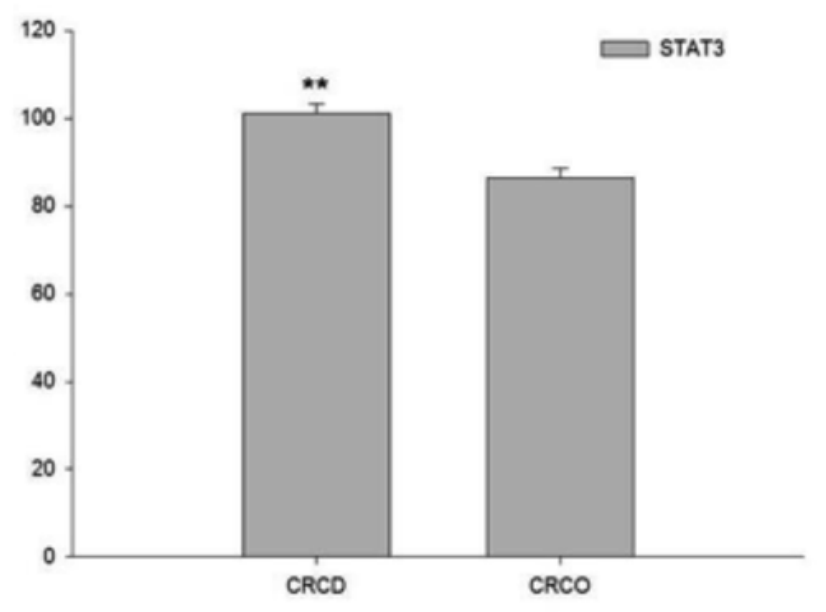

\section{Figure 9}

Effect of ART1[p-AKT $\square$ mTOR $\square S T A T 3$ on expression in balb/c mouse colorectal carcinoma complicated with diabetes mellitus in transplanted tumor. CRCD: colorectal carcinoma complicated with diabetes mellitus; CRCO: colorectal carcinoma not complicated with diabetes mellitus. ${ }^{\star *} p<0.01 \rrbracket * p<0.05 \rrbracket$ 

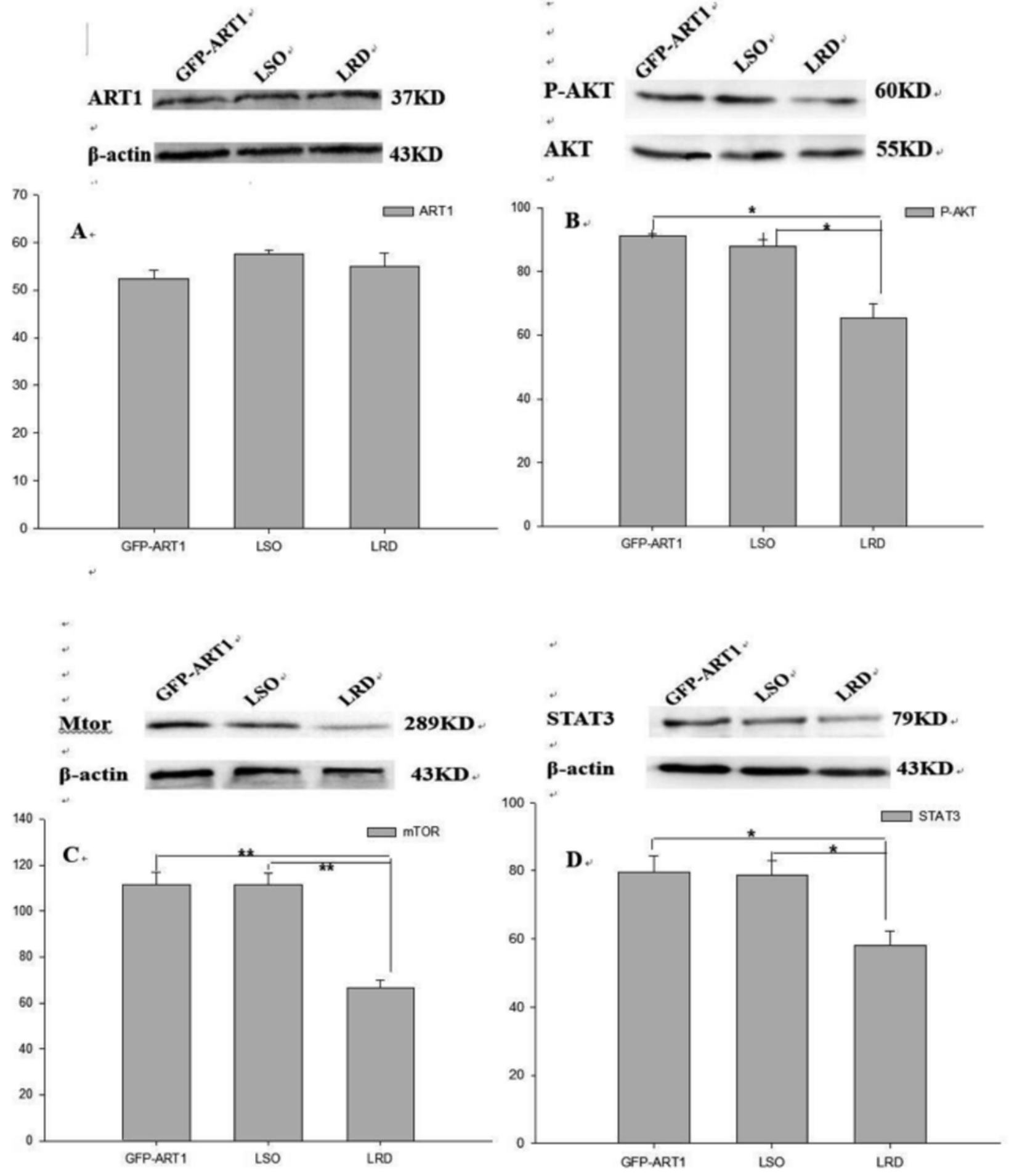

Figure 10

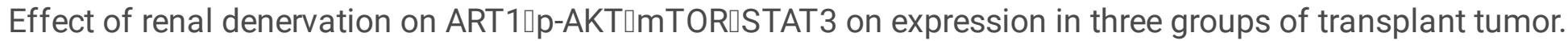
邓** $p<0.01 \rrbracket * p<0.05 \rrbracket$ 